
\title{
smananan
}

\section{Development and Validation of An Elderly Care Capacity Needs Questionnaire in Elderly Care Institutions with the Model of Combination of Medical and Health Care}

\author{
Liping Zhou \\ Changde Vocational Technical College \\ Yunfan Yang \\ Xiangya School of Nursing, Central South University \\ Xiao Xiao \\ Changde Vocational Technical College \\ Siyuan Tang ( $\nabla$ tangsyuan@126.com ) \\ Xiangya School of Nursing, Central South University \\ Yuhua Su \\ Changde Vocational Technical College
}

\section{Research Article}

Keywords: Elderly Care Institutions, Elderly Care, Capacity Needs, Questionnaire

Posted Date: July 8th, 2021

DOI: https://doi.org/10.21203/rs.3.rs-670758/v1

License: @ (i) This work is licensed under a Creative Commons Attribution 4.0 International License. Read Full License 


\section{Abstract \\ Background}

China's elderly population is growing rapidly. As the primary provider of geriatric care services, the expertise and care competencies of nursing staff directly affect the quality of services provided by elderly care institutions. To develop a geriatric care capacity needs questionnaire to provide an assessment tool for the implementation of geriatric care quality improvement and staff capacity building programs in elderly care institutions.

\section{Methods}

Based on the literature review, a questionnaire item pool was established. The initial questionnaire was formed by interviewing senior nursing staff and a pilot survey. The formal questionnaire was formed by testing the reliability and validity of the questionnaire.

\section{Results}

The Elderly Care Capacity Needs Questionnaire (ECCNQ) was composed of 12 dimensions. The Cronbach's Alpha coefficient of the total questionnaire was 0.860 . The Spearman-Brown coefficient was 0.832 , Guttman split-half coefficient was 0.83 . The correlation coefficient between each dimension and the total questionnaire was 0.472-0.737.

\section{Conclusions}

The reliability and validity of the ECCNQ are acceptable, with good stability and effectiveness, which can be used as an evaluation tool for elderly care capacity needs.

\section{Background}

United Nations population reports show the number of the elderly will soar to 2.02 billion by 2050 , and that China's elderly will reach 438 million, accounting for more than $30 \%$ of the total population. According to the State of Ageing and Health in China report published by the World Health Organization, China's population is aging faster than that of other low-income countries ${ }^{[1]}$. Therefore, the Chinese government attaches great importance to the aging of the population and actively promotes the development of elderly care. The Chinese government started vocational education in geriatric care in 1998, including professional training and short-term training. However, enrollment in geriatric nursing programs in vocational colleges is small, with less than 1,000 students enrolled each year. At the same time, the length of the study is long, typically three years. Vocational college education is far from meeting the demand for geriatric caregivers in an aging society. In contrast, short-term training can offer crash courses to help trainees pass the entry exam for elderly care institutions. This rapid and focused training can alleviate the shortage of elderly nurses to some extent ${ }^{[2]}$. Certainly, the disadvantages of short-term training are obvious: the vast majority are middle-aged women with low levels of education [3]

In China, the model of combining medical care with health care is gradually rising in elderly care institutions. Unlike traditional elderly care institutions, medical and health care institutions provide standardized and personalized care to the elderly according to their different types of chronic physical diseases and degrees of functional degeneration. The meaning of "medical" in the combination of medical and health care includes disease diagnosis, treatment, observation, and rehabilitation. The meaning of "health care" includes psychological care, diet care, environmental care, skin care, safety guidance, home environment design for the elderly, the provision of assistive devices, the introduction of relevant laws to protect the personal and property safety of the elderly, and the provision of funeral services. Assessing the demand for nursing staff knowledge and skills in integrated medical care institutions can provide targeted courses for geriatric nursing students, improving the efficiency of nursing training and the quality of geriatric nursing services.

An extensive review of the literature has identified a number of assessment tools for geriatric care needs, but there are some problems with the current assessment tools, such as fewer items, insufficient coverage, or overly broad, poorly targeted, and not very helpful measurements. Therefore, the research team strictly followed the questionnaire development procedure and developed a nursing 
capacity needs assessment questionnaire suitable for the region. The contents of the questionnaire included basic medical knowledge, nursing competence, humanistic qualities, and communication skills.

The purpose of this study is to provide support for the comprehensive evaluation of nursing capacity needs in colleges and social training institutions. It also provides a reference for the implementation of quality improvement and capacity building models for elderly care in elderly care institutions.

\section{Methods}

\subsection{Development of the Elderly Care Capacity Needs Questionnaire (ECCNQ)}

Since the purpose of the tool is to assess the effectiveness and usefulness of geriatric nursing education, it is necessary to identify the capacity needs of geriatric nursing institutions and a set of curricula needed for geriatric nursing education. To ensure that all contents are included in the ECCNQ, a comprehensive review of the existing questionnaire's literature and content analysis are carried out.

An interview survey conducted in elderly care institutions in China pointed out that geriatric nursing development includes improving the professional quality of elderly nursing staff and professional nursing construction ${ }^{[4]}$. The study points out that the improvement of elderly nursing quality mainly depends on professional nursing education. Systematic courses in geriatric nursing include life care, dementia care, dietary care, geriatric care, rehabilitation care, habilitation techniques, psychological care, communication skills, and intellectual management skills. From the perspective of the clinical needs of elderly care in China, another study believed that elderly nursing staff's core competencies were basic nursing knowledge, professional nursing competence, and professional qualifications ${ }^{[5]}$. Meanwhile, professional ethics, psychological nursing, professional nursing, dementia nursing, rehabilitation nursing, and diet nursing should be highlighted. Based on the current situation of geriatric nursing teaching in China Vocational College, another research team suggests that the curriculum of geriatric nursing includes six modules: basic medical courses, basic nursing courses, nursing humanities courses, professional nursing courses, public elective courses, and practical courses ${ }^{[6]}$. Among them, nursing professional course modules include nursing foundation, elderly nursing skills operation, geriatric clinical nursing, nursing interpersonal communication skills, community nursing, rehabilitation nursing for the elderly, psychological and spiritual nursing for the elderly, emergency nursing for the elderly, nutrition and diet therapy for the elderly.

According to Croft's study on the capacity needs of Australian nurses in geriatric care, it was found that geriatric nurses need specialized skills such as wound management skills, injection therapy, and palliative care ${ }^{[7]}$. Japanese nurses need three years of formal learning experience, including basic medical courses, professional nursing courses, and the nursing practice process. Basic medical courses include an introduction to social welfare, welfare theory of the elderly, welfare theory of the disabled, rehabilitation exercise theory, social welfare assistance technology, psychological nursing for the elderly, introduction to home economics, medicine, mental health, introduction to nursing, nursing skills and disabled nursing ${ }^{[8]}$. Japan's elderly specialist nurses have been thoroughly trained in their comprehensive abilities, including diagnosis and treatment, nursing, physical therapy, pharmacology, diet and nutrition, and nursing management. At the same time, they pay attention to multidisciplinary and interdisciplinary training. The training courses cover geriatrics, palliative care, psychological nursing, nursing research, geriatric health care, elderly acute and chronic disease management, and elderly wound care ${ }^{[9]}$. Nursing education for the elderly in the United States started early, mainly with a bachelor's degree. Courses in elderly care include health assessment, basic nursing skills, supplementary courses (such as life cycle development, nutrition, pathophysiology, pharmacology), psychology, clinical care, community and public health care, ethics, and law ${ }^{[10,11]}$. These curriculum systems combine basic knowledge with professional skills conducive to training practical nursing talents for the elderly.

Based on the literature review at home and abroad, combined with the suggestions of textbooks and monographs, a questionnaire item pool containing 40 items was initially formed after discussion with the research group ${ }^{[12,13]}$. These items include professional ethics, organizational skills, dietary care, basic nursing skills, knowledge of human body structure, physiological knowledge, IT skills, nursing home management capability, equipment improvement skills, knowledge of introduction to social welfare, mental health care, geriatric care, professional standards, research skills, sociology, aesthetics, English and physical education, geriatric economics and property management. Laws and regulations related to the elderly, computer applications, ideology and politics, home design, pathology, microbiology, medical nursing, surgical nursing, five senses nursing, nurse-patient communication skills, rehabilitation, dementia care skills, psychological care skills, emergency care, hospital infection prevention and control, hospice care, health assessment, communication skills, organizational skills, safety and security, and Chinese health care skills. 
Five nursing staff with more than five years of working experience in medical and health elderly care institutions were selected for a structured interview. Questions were reviewed by them to remove duplicates, combine concepts, and remove nonrelevant or outdated items. Finally, the ECCNQ is summarized into 12 dimensions, making the questions concise and quick to answer. The 12 dimensions include emergency care, health assessment, safety protection, knowledge of nosocomial infection, rehabilitation care, communication skills, cognitive impairment care, diet care, professional ethics, specialized care, hospice care, organizational skills.

\subsection{Participants}

The Human Research Ethics Committee of the First Affiliated Hospital of Changde Vocational Technical College approved pilot research and large sample research.

Inclusion criteria: $₫$ working years of elderly care for the aged $\geq 2$ years; $\llbracket$ voluntary participation, informed consent of the study, and signing of informed consent. 10 nursing staff who met the inclusion criteria were selected to participate in the pilot survey to test the initial version of the questionnaire's surface validity.

A stratified random sampling method was used to draw nursing staff from eight local medical and health care institutions. Participants were recruited from nursing staff in elderly care institutions via social media such as WeChat and email. The ECCNQ uses a 5-point Likert scale from " not at all" to "daily needs" on a scale of 1-5. The higher the score, the higher the need.

\subsection{Data Analysis}

SPSS software (version 26) was used to analyze the data. The critical ratio value was used to analyze the items. Exploratory Factor Analysis was used to investigate the construct validity of the ECCNQ. The reliability of the ECCNQ was evaluated by internal consistency reliability test and test-retest reliability. Cronbach's Alpha coefficient is used to measure internal consistency and reliability, which is related to the homogeneity of items in the scale and their relationship. Cronbach's Alpha coefficients between 0.70 and 0.90

are considered acceptable internal consistency ${ }^{[14-15]}$. Spearman-Brown coefficient and Guttman split-half coefficient were used to test the test-retest reliability.

\section{Results}

The results of the pilot survey showed that nursing staff in elderly care institutions were able to understand the items of the questionnaire better. Their feedback was that ECCNQ is easy to understand and applicable to the assessment of nurses' capacity needs in medical and health care institutions. The average time to fill out the questionnaire was about 10 minutes. 161 questionnaires were collected, and the recovery rate was $100 \%$. Among the 161 elderly nursing staff, there were 65 from Fushou Yikang nursing home, 14 from Jiayuan nursing home, 14 from Heshengyuan nursing home, 16 from Kangfulai nursing home, 7 in Yongfeng nursing home, 16 in Fuhai nursing home, 18 in Xiyanghong nursing home and 11 from Elderly care service center in Zou town. The scores for the capacity needs of nursing staff in medical and health care institutions are shown in Table 1. 
Table 1

Nursing staff capacity needs scores for integrated medical and health care institutions $(n=161)$

\begin{tabular}{|lllllll|}
\hline Items & $\begin{array}{l}\text { Not at } \\
\text { all }\end{array}$ & $\begin{array}{l}\text { Rarely } \\
\text { demand }\end{array}$ & $\begin{array}{l}\text { Half } \\
\text { demand }\end{array}$ & $\begin{array}{l}\text { Often } \\
\text { demand }\end{array}$ & $\begin{array}{l}\text { Daily } \\
\text { demand }\end{array}$ & Mean \pm SD \\
\hline Specialized Care & 5 & 12 & 6 & 9 & 129 & $4.47 \pm 1.07$ \\
\hline Emergency Care & 3 & 21 & 9 & 5 & 123 & $4.47 \pm 1.07$ \\
\hline Health Assessment & 4 & 22 & 14 & 12 & 126 & $4.53 \pm 1.01$ \\
\hline Safety Protection & 4 & 13 & 8 & 8 & 128 & $4.66 \pm 0.84$ \\
\hline $\begin{array}{l}\text { Knowledge of Nosocomial } \\
\text { Infection }\end{array}$ & 5 & 3 & 6 & 5 & 142 & $4.86 \pm 0.52$ \\
\hline Hospice Care & 1 & 14 & 9 & 11 & 126 & $4.56 \pm 0.94$ \\
\hline Cognitive Impairment Care & 0 & 5 & 5 & 5 & 146 & $4.81 \pm 0.36$ \\
\hline Organizational Skills & 2 & 4 & 3 & 7 & 145 & $4.84 \pm 0.57$ \\
\hline Rehabilitation Care & 0 & 6 & 3 & 9 & 143 & $4.81 \pm 0.61$ \\
\hline Communication Skills & 2 & 4 & 2 & 8 & 145 & $4.85 \pm 0.55$ \\
\hline Diet Care & 2 & 7 & 7 & 8 & 137 & $4.75 \pm 0.70$ \\
\hline Professional Ethics & 5 & 5 & 5 & 5 & 141 & $4.81 \pm 0.63$ \\
\hline
\end{tabular}

\subsection{Item Analysis}

The first $27 \%$ was defined as the low group, and the last $27 \%$ was the high group. The independent-sample t-test was used to compare the difference between the two groups. The absolute value of $C R<3.000$ and not significant $(P>0.05)$ was taken as the deletion standard ${ }^{[16]}$. The data collected from 161 valid questionnaires showed that each item's scores were significantly different $(P=0.000)$, and the CR was above 3.000, as shown in Table 2.

Table 2

The results of item analysis

\begin{tabular}{|lcccccc|}
\hline Items & CR $(\mathbf{t})$ & $\mathbf{P}$ & Mean & SE & \multicolumn{2}{l|}{ Cl (95\%) } \\
\cline { 7 - 7 } & & & & & Lower limits & Upper limits \\
\hline Emergency Care & -9.186 & 0.000 & -1.756 & 0.191 & -2.141 & -1.370 \\
\hline Health Assessment & -8.218 & 0.000 & -1.578 & 0.192 & -1.965 & -1.191 \\
\hline Safety Protection & -6.240 & 0.000 & -1.156 & 0.185 & -1.529 & -0.782 \\
\hline Knowledge of Nosocomial Infection & -3.338 & 0.002 & -0.444 & 0.133 & -0.713 & -0.176 \\
\hline Rehabilitation Care & -3.903 & 0.000 & -0.600 & 0.154 & -0.910 & -0.290 \\
\hline Communication Skills & -3.272 & 0.002 & -0.422 & 0.129 & -0.682 & -0.162 \\
\hline Cognitive Impairment Care & -3.765 & 0.000 & -0.556 & 0.148 & -0.853 & -0.258 \\
\hline Diet care & -5.360 & 0.000 & -0.889 & 0.166 & -1.223 & -0.555 \\
\hline Professional Ethics & -3.893 & 0.000 & -0.622 & 0.160 & -0.944 & -0.300 \\
\hline Specialized Care & -5.399 & 0.000 & -1.022 & 0.189 & -1.404 & -0.641 \\
\hline Hospice Care & -7.845 & 0.000 & -1.467 & 0.187 & -1.843 & -1.090 \\
\hline Organizational Skills & -3.697 & 0.001 & -0.533 & 0.144 & -0.824 & -0.243 \\
\hline
\end{tabular}

\subsection{Construct validity}


After item analysis, Exploratory Factor Analysis was used to test the construct validity. Kaiser Meyer Olkin measure of sampling adequacy test (KMO) and Bartlett's spherical test are needed to test whether exploratory factor analysis is suitable ${ }^{[17]}$. KMO value $\geq$ 0.6 and the spherical test has a statistical difference $(P<0.05)$ is suitable for exploratory factor analysis ${ }^{[18]}$. The analysis results of 161 questionnaires showed that the KMO value was 0.762 . Bartlett's sphericity test showed a significant difference ( $p=0.000)$, suitable for factor analysis, as shown in Table 3. These 12 dimensions have common factors and can be subjected to principal component factor analysis. The results of infinite extraction factor rotation, factor loading matrix and commonality are shown in Table 4 . The results of the analysis showed that the loadings of the 12 dimensions exceeded the significance of 0.45 . The results of the contribution and eigenvalue of each dimension are shown in Table 5. The correlation coefficient between each dimension and the total questionnaire was $0.472-0.737$, as shown in Table 6.

Table 3

The results of the $\mathrm{KMO}$ and Bartlett test

\begin{tabular}{|lll|}
\hline KMO sampling suitability quantity & $\mathbf{0 . 7 6 2}$ \\
\hline Bartlett's sphericity test & Approximate chi square & 846.171 \\
\cline { 2 - 3 } & freedom & 66 \\
\cline { 2 - 2 } & Significance & 0.000 \\
\hline
\end{tabular}

Table 4

The results of the component matrix after rotation

\begin{tabular}{|c|c|c|c|}
\hline \multirow[t]{2}{*}{ Items } & \multicolumn{2}{|c|}{ Component } & \multirow[t]{2}{*}{ Commonalty } \\
\hline & 1 & 2 & \\
\hline Health Assessment & 0.820 & & 0.692 \\
\hline Emergency Care & 0.769 & & 0.604 \\
\hline Hospice Care & 0.741 & & 0.613 \\
\hline Safety Protection & 0.677 & & 0.483 \\
\hline Specialized Care & 0.646 & & 0.464 \\
\hline Diet care & 0.586 & & 0.489 \\
\hline Organizational Skills & & 0.808 & 0.655 \\
\hline Knowledge of Nosocomial Infection & & 0.755 & 0.635 \\
\hline Rehabilitation Care & & 0.701 & 0.600 \\
\hline Professional Ethics & & 0.682 & 0.487 \\
\hline Cognitive Impairment Care & & 0.671 & 0.495 \\
\hline Communication Skills & & 0.529 & 0.311 \\
\hline
\end{tabular}


Table 5

The results of an explanation of the total variance

\begin{tabular}{|c|c|c|c|c|c|c|c|c|c|}
\hline \multirow[t]{2}{*}{ Items } & \multicolumn{3}{|c|}{ Initial eigenvalue } & \multicolumn{3}{|c|}{$\begin{array}{l}\text { Extract the sum of squares of } \\
\text { loads }\end{array}$} & \multicolumn{3}{|c|}{ Sum of squares of rotating loads } \\
\hline & Total & $\begin{array}{l}\text { Variance } \\
\text { percentage }\end{array}$ & $\begin{array}{l}\text { Cumulative } \\
\text { percentage }\end{array}$ & Total & $\begin{array}{l}\text { Variance } \\
\text { percentage }\end{array}$ & $\begin{array}{l}\text { Cumulative } \\
\text { percentage }\end{array}$ & Total & $\begin{array}{l}\text { Variance } \\
\text { percentage }\end{array}$ & $\begin{array}{l}\text { Cumulative } \\
\text { percentage }\end{array}$ \\
\hline $\begin{array}{l}\text { Emergency } \\
\text { Care }\end{array}$ & 4.915 & 40.959 & 40.959 & 4.915 & 40.959 & 40.959 & 3.304 & 27.534 & 27.534 \\
\hline $\begin{array}{l}\text { Health } \\
\text { Assessment }\end{array}$ & 1.614 & 13.447 & 54.406 & 1.614 & 13.447 & 54.406 & 3.225 & 26.872 & 54.406 \\
\hline $\begin{array}{l}\text { Safety } \\
\text { Protection }\end{array}$ & 0.989 & 8.241 & 62.647 & & & & & & \\
\hline $\begin{array}{l}\text { Knowledge of } \\
\text { Nosocomial } \\
\text { Infection }\end{array}$ & 0.919 & 7.658 & 70.304 & & & & & & \\
\hline $\begin{array}{l}\text { Rehabilitation } \\
\text { Care }\end{array}$ & 0.754 & 6.285 & 76.589 & & & & & & \\
\hline $\begin{array}{l}\text { Communication } \\
\text { Skills }\end{array}$ & 0.670 & 5.584 & 82.174 & & & & & & \\
\hline $\begin{array}{l}\text { Cognitive } \\
\text { Impairment } \\
\text { Care }\end{array}$ & 0.594 & 4.953 & 87.127 & & & & & & \\
\hline Diet care & 0.465 & 3.878 & 91.005 & & & & & & \\
\hline $\begin{array}{l}\text { Professional } \\
\text { Ethics }\end{array}$ & 0.400 & 3.334 & 94.339 & & & & & & \\
\hline $\begin{array}{l}\text { Specialized } \\
\text { Care }\end{array}$ & 0.280 & 2.333 & 96.672 & & & & & & \\
\hline Hospice Care & 0.244 & 2.030 & 98.702 & & & & & & \\
\hline $\begin{array}{l}\text { Organizational } \\
\text { Skills }\end{array}$ & 0.156 & 1.298 & 100.000 & & & & & & \\
\hline
\end{tabular}

Table 6

The results of Pearson correlation analysis

\begin{tabular}{|cllllll|}
\hline & Emergency Care & $\begin{array}{l}\text { Health } \\
\text { Assessment }\end{array}$ & $\begin{array}{l}\text { Safety } \\
\text { Protection }\end{array}$ & $\begin{array}{l}\text { Knowledge of Nosocomial } \\
\text { Infection }\end{array}$ & $\begin{array}{l}\text { Rehabilitation } \\
\text { Care }\end{array}$ & $\begin{array}{l}\text { Communication } \\
\text { Skills }\end{array}$ \\
\hline $\mathrm{R}$ & 0.695 & 0.737 & 0.628 & 0.645 & 0.670 & 0.472 \\
\hline $\mathrm{P}$ & 0.000 & 0.000 & 0.000 & 0.000 & 0.000 & 0.000 \\
\hline & $\begin{array}{l}\text { Cognitive } \\
\text { Impairment Care }\end{array}$ & Diet care & $\begin{array}{l}\text { Professional } \\
\text { Ethics }\end{array}$ & Specialized Care & Hospice Care & $\begin{array}{l}\text { Organization } \\
\text { Skills }\end{array}$ \\
\hline $\mathrm{R}$ & 0.582 & 0.681 & 0.544 & 0.643 & 0.737 & 0.545 \\
\hline $\mathrm{P}$ & 0.000 & 0.000 & 0.000 & 0.000 & 0.000 & 0.000 \\
\hline
\end{tabular}

\subsection{Reliability Analysis}

The Cronbach's Alpha coefficient of the total questionnaire was 0.860 . The spearman-Brown coefficient was 0.832 , Guttman split-half coefficient was 0.83 , as shown in Table 7.

Table 7

The results of reliability analysis

\begin{tabular}{|lll|}
\hline Cronbach's a & Spearman-Brown & Guttman Split-Half \\
\hline 0.860 & 0.832 & 0.83 \\
\hline
\end{tabular}

Page $7 / 10$ 


\subsection{Acceptability of the questionnaire}

In this study, the questionnaire's recovery rate reached $100 \%$, and the effective rate was $100 \%$. It took an average of 10 minutes for the elderly nursing staff to fill in the questionnaire. Participants' feedback was that the questionnaire items' design was simple, easy to read and write, and the length of the items was acceptable.

\section{Discussions}

This study found the structure of the staff of the combined health and nursing care facilities. Most managers were women in their $30 \mathrm{~s}$ who were not nursing majors and had college degrees. The skills required of them by the institutions were proficiency in the use of computers for documentation and organization and management. The nursing staff, on the other hand, is the group that directly cares for the elderly and is between 45 and 60 years old; they are poorly educated, poorly paid, and highly mobile, with few working for more than five years. In addition, nursing staff of nursing institutions cannot participate in the professional title of nursing.

Moreover, different from clinical nursing, the elderly nursing staff in combined medical and health care institutions need life nursing skills and clinical professional nursing skills. Therefore, the staff who have worked in elderly care institutions with the mode of combination of medical and health care for more than five years were consulted due to the lack of local theoretical experts with rich practical experience in elderly care institutions, after the preliminary formulation of the item pool of this questionnaire ${ }^{[20]}$. Finally, the 40 item pools were summarized into 12 dimensions more suitable for actual work needs than Delphi expert consultation.

Item analysis of 161 valid questionnaires showed a significant difference between each item and the total score of the ECCNQ, and the CR was above 3.000, which was statistically significant. The ECCNQ construction procedure was reasonable. Although there is a nurse capacity needs assessment tool, there is a lack of specific questionnaire tools for health care integrated geriatric care institutions. There are 40 items in the ECCNQ. The average time taken for the participants to fill in the ECCNQ is 10 minutes. The participants' feedback is that the content of the items is easy to read, easy to fill in, and takes a short time. Compared with the existing assessment tools, the ECCNQ has reliability and validity and provides a scientific tool for evaluating nursing staff in elderly care institutions.

The reliability of the ECCNQ is evaluated by the internal consistency test and test-retest reliability. The Cronbach's Alpha coefficient of the total questionnaire was 0.860 , indicating that the ECCNQ has good internal consistency, and all items can measure the topic of nurses' capacity needs in elderly care institutions. The spearman-Brown coefficient was 0.832 , and the Guttman split-half coefficient was 0.83 , indicating that the ECCNQ was stable.

In terms of construct validity, only Exploratory Factor Analysis was conducted in this study. The KMO was 0.762 , and Bartlett's sphericity test showed a significant difference $(p=0.000)$. Factor analysis was appropriate. Infinite decimation factor analysis was performed. The minimum factor load is 0.529 , and the load of 12 dimensions is more than 0.4 , indicating that the dimensions were representative ${ }^{[19]}$. The commonality of communication skills was 0.311 , lower than 0.4 , which should be deleted. However, after consulting nursing staff in elderly care institutions many times, it was found that the demands for this ability were undeniable, and the application of communication skills ranked first in daily work. Therefore, combined with the actual situation of nursing work, this dimension should be retained. Besides, there are only two dimensions with factor eigenvalue $\geq 1$, and the cumulative contribution rate of variance contribution rate reaches $54 \%$. The first two-factor rotational analysis found the lowest contribution of organizational capacity at $1.298 \%$, which should be removed. However, the nursing staff has applied organizational skills every day, including organizing and carrying out various nursing work. Generally, the nursing staff was assigned to serve 7 to 8 older adults. Therefore, the research group decided that the questionnaire dimension should not be divided into two modules, and no factor extraction analysis was carried out. Pearson correlation analysis showed that the correlation coefficient between each dimension and the total questionnaire was $0.472-0.737$ (all $\mathrm{P} \leq 0.01$ ). Except for the correlation coefficient of communication skills was 0.472 , the other dimensions were above 0.5 , indicating that each dimension's measurement contents belong to the same subject. This result also shows that the dimensions are different but cannot replace each other.

Due to time and sample limitations, confirmatory factor analysis and calibration validity evaluation were not carried out in this study. Future research can expand the sample to confirmatory factor analysis and use predictive validity to test the questionnaire's calibration validity in the case of sufficient time. Participants in this study were 161 nursing staff from 8 local elderly care institutions, with insufficient coverage and poor representation. Therefore, further research will use the ECCNQ to carry out large sample measurements of multiregional cooperation to test the reliability and validity to increase the popularization of the ECCNQ.

Page $8 / 10$ 


\section{Conclusions}

The results indicated that the ECCNQ has good reliability, validity and comprehensive items, which is the result of strict adherence to the questionnaire development procedures. Therefore, the ECCNQ can be used as a tool to measure the nursing capacity needs of nursing staff in elderly care institutions and provide a basis for developing a geriatric care training curriculum and improving the quality of geriatric care.

\section{Abbreviations}

\section{ECCNQ}

The Elderly Care Capacity Needs Questionnaire

IT

Information Technology

CR

Critical Ratio

KMO

Kaiser-Meyer-Olkin measure

\section{Declarations}

Ethical approval: This study was approved by the Human Research Ethics Committee of the First Affiliated Hospital of Changde Vocational Technical College (Changde, China).

Consent for publication: Written informed consent for publication was obtained from all participants.

Availability of data and materials: All data generated or analyzed during this study are included in this published article.

Funding Statement: This study was supported by grants from the Education Department of Hunan Province (ZJGB2019226).

Authors' contributions: YYF and ZLP are joint first authors. ZLP, YYF, XX and SYH obtained funding. ZLP, YYF and TSY were responsible for the design of the study, and organized and coordinated all aspects of the research. ZLP, XX and SYH collected and analyzed the data. ZLP and YYF was responsible for drafting the article and TSY revised it critically for important intellectual content. All authors have read and approved the final manuscript.

Acknowledgements: The authors would like to acknowledge the following: the administrators and staff of cooperative elderly care institutions in Changde city. Yang Peng for cooperation in collecting, collating and analyzing data.

Competing interests: No conflicts of interest are reported.

\section{References}

1. World Health Organization. National assessment report on aging and health in China[R]. 2016.

2. The Ministry of Human Resources and Social Security and the Ministry of Civil Affairs promulgated and implemented the national occupational skill standard for nursing staff for the aged (2019 Edition) [J]. China standardization, 2019 (21).

3. Liu Shenmei, Zhuang Huaying. Status and Countermeasures of nursing staff in elderly care institutions in Changde City[J]. Chinese geriatric health medicine. 2012 (10), 3:55-56.

4. Ren jiehui. From incomplete to systematic: Research on the professional development of elderly nursing in China[J]. Ideological front. 2019,45(3):142-149.

5. Li Jin, Yang Mingxian, Fan Xinte. Composition and improvement of core competence of nursing professionals in geriatrics[J]. Friends of health, 2019.12:191.

6. Min GUI, Zhao Guoqin, Wang Aiqin. Research on the curriculum design of elderly nursing specialties in Higher Vocational Colleges under the demand's orientation [J]. China Medical Guide, 2020, 17 (2): 62-650.

7. CROFT H.The Australian Care: A Training Manual for Aged Care Workers[M].Melbourne, Vic: Cengage Australia,2016. 
8. Dai Weidong. Comparison and thinking of long-term nursing education and training system between Japan and Korea [J]. Aging science research, 2015,3 (10): 72-79.

9. Sun Zi Keji mu, Zhang Baolu, Wang Hongya (review), et al. Current situation and thinking of nursing personnel training in medical and nursing care integrated pension institutions [J]. Journal of Nursing, 2016, 23 (023): 31-34.

10. Scott-Tilley D, Marshall-Gray P, Valadez A, et al. Integrating long-term care concepts into baccalaureate nursing education: the road to quality geriatric health care. [J]. Journal of Nursing Education, 2005, 44(6):286-290.

11. Moffatt E K. Gerontological Nursing: Competencies for Care[J]. Aorn Journal, 2010, 91(1):183-184.

12. Liu Xiaochu, Gu Li, Sun Zi Keji mu, et al. Development and reliability and validity test of Kano attribute questionnaire on elderly service demands in medical and nursing care integrated elderly care institutions[J]. Chinese Journal of General Practice, 2020,23(27): 3449-3456.

13. Xi Yangjuan, Zhang Wenguang, Li Xiaoyu, et al. Construction and reliability and validity test of evaluation index system for core competence of nursing professionals in a combination of medical and nursing [J]. Nursing Research, 2020, 34 (1): $79-85$

14. An Shengli, Chen Pingyan. Reliability and influencing factors of the scale [J]. Chinese Journal of clinical psychology, 2001 (04): 315-318.

15. Su Zhonghua, Li Siquan, Cheng Yiren. Internal consistency of scale evaluation and application evaluation of Cronbach a coefficient [J]. Journal of Clinical Psychosomatic Diseases, 2009, 15 (1): 85-86.

16. Hu Jing. Research on the conceptual framework and evaluation tools of nurses' sense of benefit [D]. Second Military Medical University, 2013

17. Pett, Marjorie A., Nancy R. Lackey, and John J. Sullivan. Making sense of factor analysis: The use of factor analysis for instrument development in health care research[M]. SAGE, 2003.

18. Yao Wanqing. Development and application of cognitive scale of continuous care for premature infants for main caregivers [D], Anhui Medical University, 2017.

19. Wu Minglong. SPSS operation and application of questionnaire statistical analysis practice [M], Chongqing University Press, 2010.5:181-182

20. Wang Shaona, Dong Rui, Xie Hui, et al. Application progress of Delphi method and its construction index system [J]. Journal of Bengbu Medical College, 2016,41 (05): 695-698. 